\title{
Posibles alteraciones locales y sistémicas de los piercings orales y periorales
}

\author{
Escudero Castaño $\mathrm{N}^{*}$, Bascones Martínez A**
}

\section{RESUMEN}

A lo largo de la historia, la sociedad ha ido decorando su cuerpo de diferentes formas, como los piercing; y que en los últimos tiempos es una tendencia que ha incrementado su uso entre la población adulta joven. Esta ha sido una antigua forma de modificación del cuerpo que conlleva ciertos significados, tanto religiosos, como culturales, sociales, etc. En este artículo, describiremos la historia, tipos y localizaciones de los piercings orales y periorales, contraindicaciones, cuidados que debemos llevar a cabo para evitar complicaciones, así como posibles alteraciones y el tratamiento ante éstas.

Palabras clave: Piercing oral y perioral, contraindicaciones, alteraciones orales, tratamiento odontológico.

\section{SUMMARY}

Though out history, society has been decorating its body in different ways; one of them is the oral and perioral piercing, even though nowadays this is a tendency that increases among the young-adult population. This is an ancient form of modifying the body which implies certain significance such as religious, cultural and social. This article will outline its history, the types and locations of the oral and perioral piercings, its contraindications, and treatment that should be taken to avoid complications, possible alterations, and the treatment after it.

Key words: Oral and perioral piercing, contraindications, oral alterations, odontologic treatment.

Fecha de recepción: Junio 2006.

Aceptado para publicación: Octubre 2006.

* Odontóloga. Curso de experto en periodoncia.

** Catedrático de Medicina Bucal y Periodoncia. Facultad de odontología. Universidad Complutense de Madrid.

Escudero Castaño N, Bascones Martínez A. Posibles alteraciones locales y sistémicas de los piercings orales y periorales. Av. Odontoestomatol. 2007; 23 (1): 21-33.

\section{INTRODUCCIÓN}

Históricamente, el piercing oral y perioral han existido a lo largo de muchas culturas como un rito de paso, frecuentemente como componente religioso, tribal, sexual, o como norma de casta. Hoy en día, es más como una expresión de "independencia personal" o fashion (1).

Ya desde el antiguo Egipto se perforaban el ombligo en señal de realeza (2).
Los antiguos mayas perforaban el labio, lengua, nariz y orejas con las joyas más caras que podían permitirse en señal de espiritualidad, virilidad y coraje.

Los esquimales y los aleuts fueron los primeros que denominaron a los piercing "labrets" y en su cultura se practicaba en el labio inferior de los adolescentes, durante el paso de niño a adulto con cualidades y aptitudes para salir de caza con sus mayores. También se colocaban en los labios de las niñas recién nacidas como acto de purificación (3). Otro 
Fig. 1. Es una de las primeras representaciones pictóricas de los piercing, que data de 1500 a.C. en el antiguo Egipto. Se trata de un perro egipcio que piercing, como símbolo de su realeza.

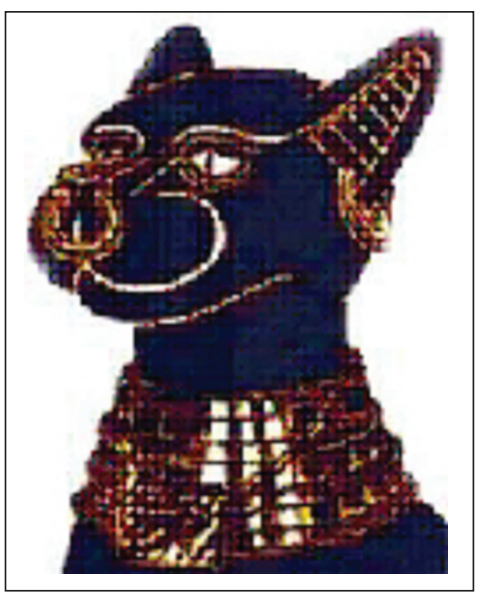

de los orígenes de la perforación corporal está en las tribus masai, en concreto en la población femenina, que deforman su cavidad bucal con discos para aumentar de tamaño la boca y alargan sus lóbulos llevando unos carretes metálicos de gran tamaño. Otras personas, particularmente los chinos e hindúes, perforan los labios, mejillas o lengua con una idea de práctica religiosa (4).

Con la llegada del cristianismo a Europa y América los piercing tuvieron un periodo de decadencia.

En Norte América se colocaron piercing por tradiciones nativas americanas (5). Aun hoy en día, en los países orientales se perforan por causas religiosas y prácticas ceremoniales. En el sur de la India se colocaban en la lengua como voto silencio (3).

Desde hace más de 20 años el movimiento punk de los años 70 puso de moda el piercing en países occidentales (6).

Hasta estos últimos años, en los países del tercer mundo se siguen perforando por motivos religiosos, tribales, mantales y sexuales. En tribus como la Sume de Etiopía colocaban grandes platos en labios inferiores. Por otra parte, en la Suya de Brasil, los hombres casados que se quedan viudos colocan discos de madera pintados. Otras tribus colocan ganchos en labios superiores o inferiores $(2,3)$.

Actualmente casi un $8 \%$ de la población que sobrepasa los 14 años lleva algún tipo de piercing corpo- ral, excluyendo los del lóbulo de la oreja, llegando a tener significados tales como riesgo, moda, atrevimiento o sexual. Al conjunto de tatuajes, piercings, escarificaciones y marcas con hierro candente han pasado a denominarse "body art" (6).

\section{MATERIALES}

Lo ideal sería el uso de materiales hipoalérgicos y no tóxicos, es decir, metales no tóxicos como Oro $14 \mathrm{~K}$ y 18 K, Titanio, acero inoxidable, Niobio; y también el plástico (tygon), acrílico, piedra, madera, hueso, marfil u combinación de los anteriores (3-5, 7). Evitar el uso de plata, bronce, cobre y chapados en oro por las posibles reacciones alérgicas y toxicidades que éstos pueden desarrollar.

El oro es un material con escasa toxicidad, aunque determinadas personas presentan algún tipo de sensibilidad. El titanio no presenta una gran citotoxicidad y tiene una elevada resistencia a la corrosión en contacto con los fluidos orgánicos, como la saliva o la sangre, siendo material de elección para los piercing orales y periorales. El acero inoxidable posee una buena biocompatibilidad, aunque una de sus principales limitaciones es su tendencia a la corrosión por su contenido en $\mathrm{Cr}$ y $\mathrm{Ni}$, elementos con efectos tóxicos y carcinogenéticos.

\section{TIPOS DE PIERCING ORALES Y PERIORALES}

Según su forma los clasificaríamos en:

1. Labret: Constituido por una barra con un extremo limitado por una bola o disco o lanza o punta y en el otro por un cierre en forma de un disco plano y liso. Normalmente localizado en el labio inferior y mentón $(3,6)$.

2. Barbell: Barra recta o curva limitada en sus dos extremos por objetos esféricos, uno de ellos hace de cierre. En el momento de la perforación la longitud de la barra no debe ser menor de unos $20 \mathrm{~mm}$, por la inflamación de la lengua, a las 2 semanas se podrá cambiar la barra a una de menor longitud. Se coloca normalmente en lengua y frenillo lingual y con menos frecuencia en úvula $(3,6)$. 


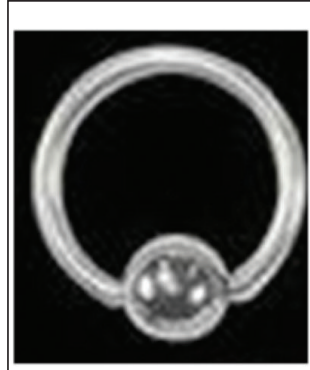

1

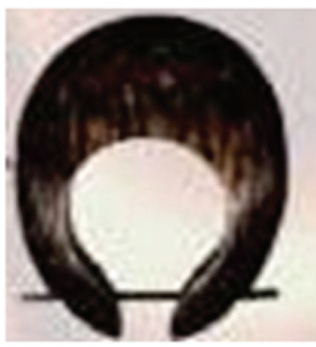

2

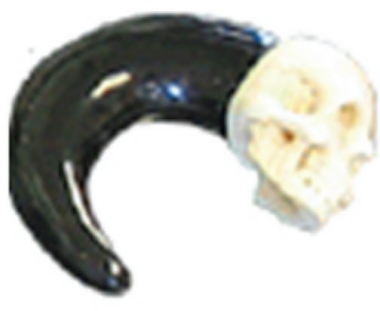

3

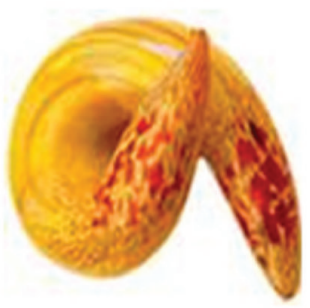

4

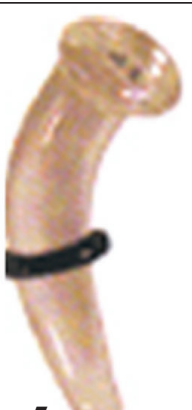

5

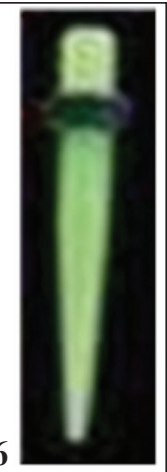

Fig. 2. De izquierda a derecha tenemos los diferentes materiales de los que puede estar compuesta la joya: (1) piercing de acero inoxidable, (2) piercing de madera, (3) piercing de hueso (4) piercing de marfil, (5) piercing de piedra, (6) piercing de plástico.

3. Anillo: Barra de forma circunferencial con 1 ó 2 bolas en su o sus extremos. Se colocan en los labios y en menor frecuencia en zonas laterales de la lengua y úvula $(3,6)$.

Según su localización los clasificaríamos en:

1. Lengua: Es la localización más frecuente de piercing bucal. Se pueden realizar dos tipos de perforaciones: La primera en la zona dorsoventral, la perforación se realiza en esta dirección en la línea media, anterior al frenillo lingual, suelen colocarse barbells $(3,5,6)$; el segundo tipo sería en partes más laterales de la lengua y en la punta se colocan más habitualmente anillos. El tiempo de cicatrización de la perforación en la lengua es aproximadamente entre 4-6 semanas después del proceso, si no ha habido ningún tipo de complicación (8). En un estudio de Maresma et al, se apreció que la localización lateral de la lengua es la que se alza con mayor cantidad de hallazgos clínicos, 13 para un 29,54\% del total de 44 descubrimientos observados en su estudio (2).

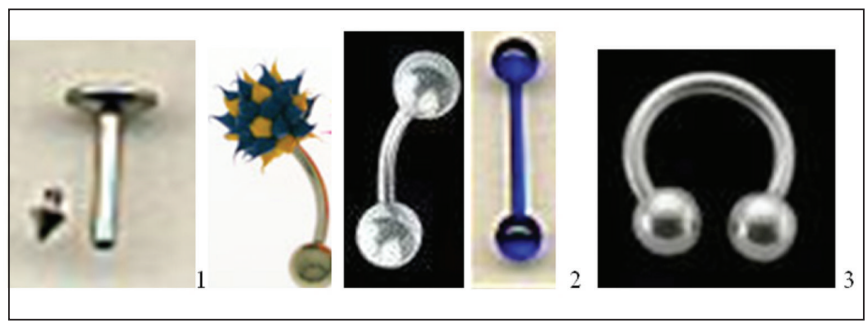

Fig. 3. 1: labret; 2: barbell; 3: anillo.

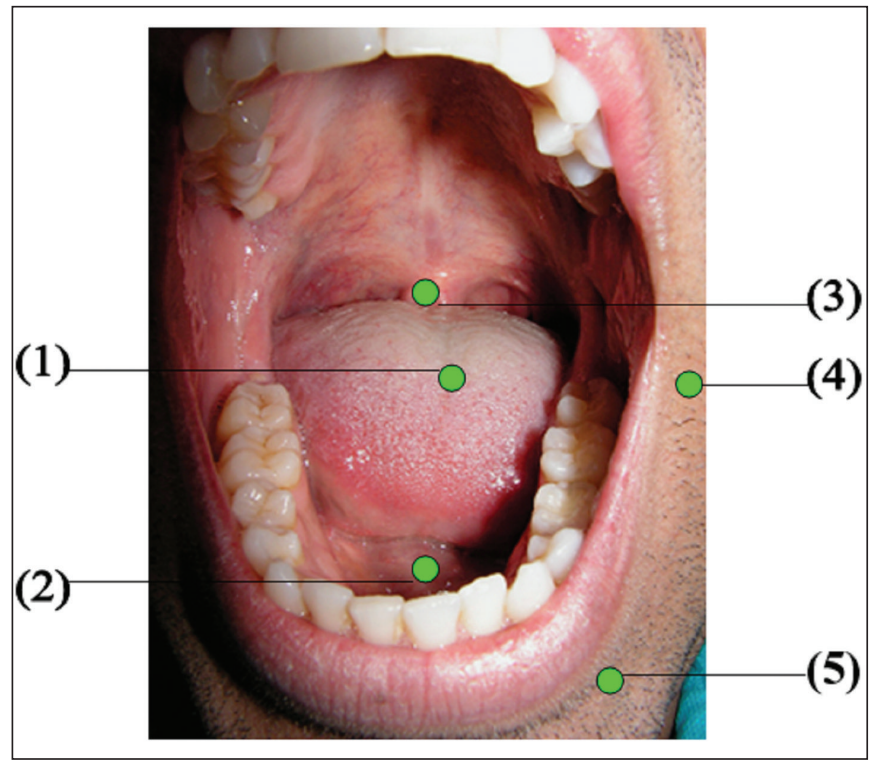

Fig. 4. Diferentes localizaciones de los piercing orales en la lengua: (1) lengua, (2) frenillo lingual, (3) úvula, (4) mejilla, (5) labio.

2. Labio: Es la segunda localización más frecuente. Puede ser perforado en múltiples localizaciones alrededor del bermellón. El piercing más usado en esta localización son los anillos, aunque también se podía colocar un labret. Las perforaciones se realizan desde fuera hacia el interior de la cavidad oral. El tiempo promedio de cicatrización es de unas 6 semanas $(3,6)$.

3. Mejilla: También conocidos como "dimples": Son poco frecuentes. La perforación llega hasta la mucosa yugal y el piercing es externo (6). 

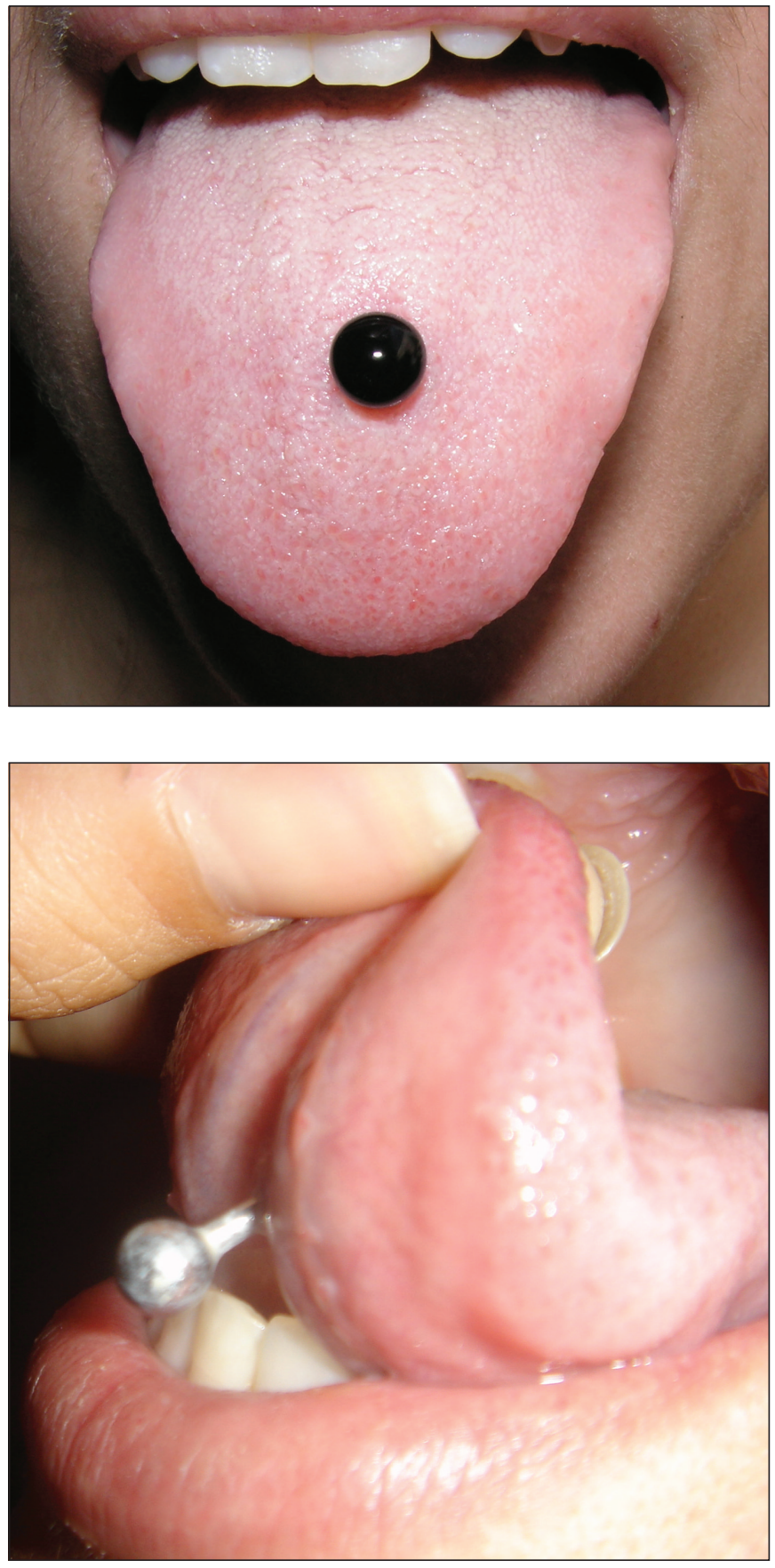

Figs. 5 y 6. Piercings barbells de tallo corto con un extremo metálico y el otro de tygon.

4. Frenillo lingual: Denominados también "Web" piercing. Son poco frecuentes. La joya en esta localización contribuye a recesiones gingivales en la región antero inferior causadas por un trauma físico sobre el tejido (3).

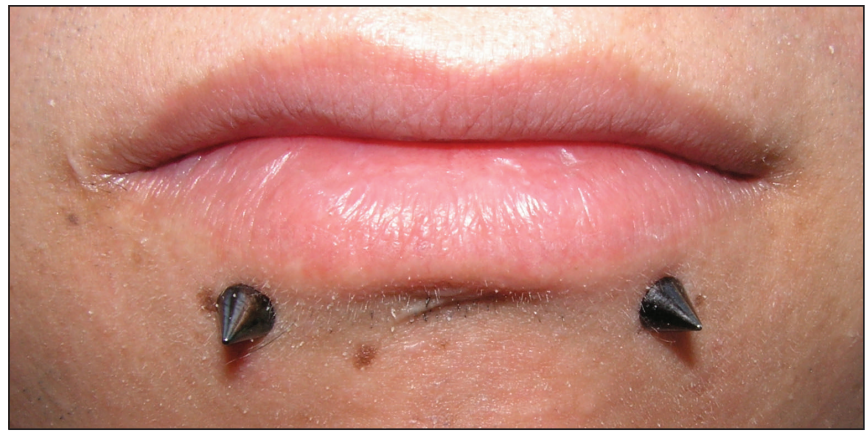

Fig. 7. Dos labrettes con el extremo intraoral plano y el extraoral en forma de punta, típicos para labios.

5. Úvula: Son los menos frecuentes de todos debido a la oposición de algunos profesionales en hacerlos y por los altos riesgos a obstrucción de vías aéreas. Se pueden ver piercing de anillo y también barbells.

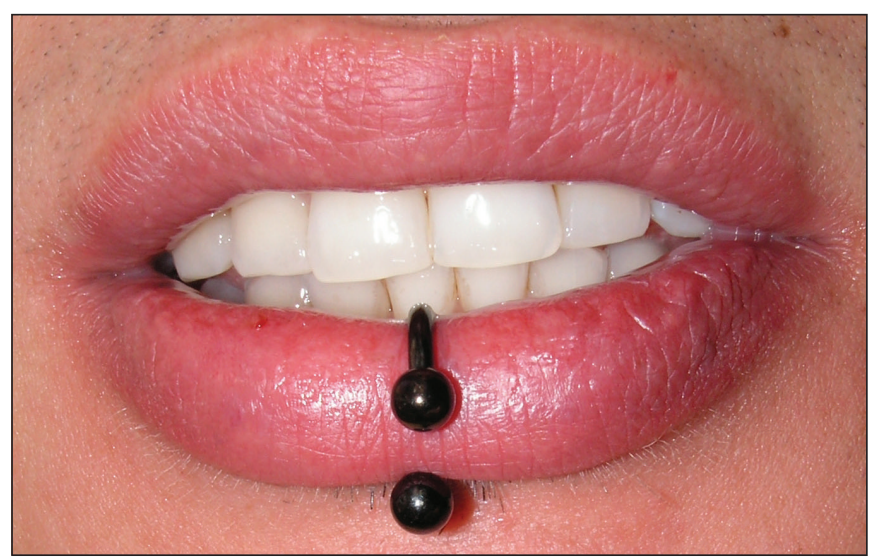

Fig. 8. Piercing de anillo, los más frecuentes en labio inferior.

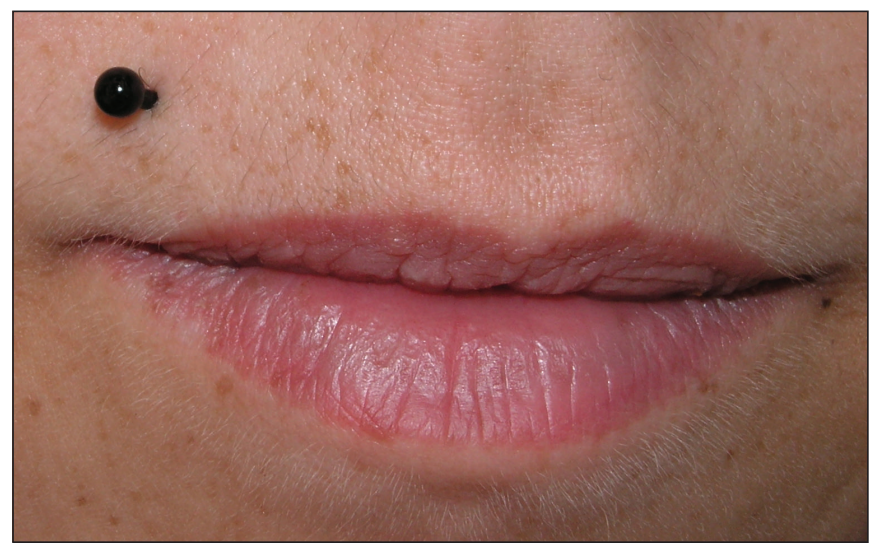

Fig. 9. Piercing de labret, también usados en labio, aunque con menor frecuencia. 


\section{RELACIÓN DE LOS PIERCING CON SUSTANCIAS ADICTIVAS}

En el estudio de Sean et al se concluye con que los tatuajes y piercings son marcadores conductuales de riesgo en jóvenes de 12 a 22 años en Estados Unidos y también se ha demostrado una mayor relación con el uso de drogas duras (cocaína, éxtasis, etc) y blandas (marihuana, tabaco y alcohol) (9).

Según Irja Ventä et al en Helsinki halló entre 234 estudiantes del primer curso de universidad, noto una mayor prevalencia de tabaco y drogas en el grupo estudio (10).

En cambio, Leichter et al no demuestra una mayor influencia de desarrollo de la recesión gingival en pacientes fumadores (11).

\section{CUIDADOS}

\section{PostcirugíA}

La limpieza es importante, durante al menos 6 semanas se deben limpiar exhaustivamente después de comidas, bebidas y tabaco, debiendo usar enjuagues antisépticos. Cuando se van a realizar mas enjuagues diarios de los recomendados, es necesario rebajar la solución bucal con agua al 50\% para evitar ulceraciones.

Evitar el consumo de tabaco, alcohol, grasas, drogas, etc, puesto que son irritantes y retrasan la cicatrización; así como se aconseja cambiar de cepillo, ya que podía quedar alguna bacteria residual que provocase infecciones.

Es necesario evitar el jugueteo o manoseo de la joya y los enjuagues hasta la cicatrización de la zona perforada.

\section{MANTENIMIENTO DEL PIERCING}

Dedicar especial atención a los signos de infección: enrojecimiento, hinchazón, supuración, olor desagra- dable, sarpullido en el área perforada o alrededor de la zona y fiebre.

Se aconseja la visita asidua al dentista ya que pueden provocar lesiones en dientes y encías.

\section{CONTRAINDICACIONES DE LOS PIERCING ORALES Y PERIORALES}

En mujeres embarazadas en caso de emergencia posparto presentaría dificultades a la hora del manejo de las vías aéreas como pueden ser el sangrado y el edema en el caso de laringoscopia o extubación (12). Generalmente se produce una mayor inflamación de las encías con lo que la presencia del piercing produciría un efecto traumático continuo con el consecuente sangrado de las encías.

En los que tienen enfermedades que alteran la cicatrización, tales como la diabetes.

Los individuos con infecciones en piel Herpes, verrugas, o infecciones bacterianas.

Para las personas con enfermedades en la piel tales como psoriasis o vitíligo no es aconsejable la colocación de la joya.

No se recomienda su colocación en personas con tendencia a cicatrices queloides, hipertróficas, fibrosas y benignas.

Contraindicación absoluta en alérgicos al material de la joya o adorno.

En personas que reciben o recibieron un medicamento llamado isotretinoína (Roa cutan) para el tratamiento del acné no debían perforarse, ya que produce alteraciones en el proceso de cicatrización pudiendo alterar la funcionalidad de la lengua.

En personas que padecen enfermedades cardíacas congénitas por el riesgo de endocarditis (13).

No recomendable el uso del piercing en personas tratadas con anticoagulantes por el riesgo de hemorragia. 


\section{POSIBLES ALTERACIONES CAUSADAS POR PIERCINGS ORALES Y PERIORALES}

Las complicaciones que pueden derivarse de los piercing orales y periorales no solo se producen durante la perforación, sino también en cualquier momento a lo largo de la vida de la joya en el cuerpo. Es importante, para la salud oral del paciente, el ponerle al corriente de todos los posibles efectos indeseables que puede llegar a producirle el piercing. Según Troye et al (3) estas alteraciones podrían llegar a ocurrir a durante el procedimiento, a corto plazo y a largo plazo, aprovechando su razonamiento, crearemos la siguiente tabla de clasificación de patologías locales y sistémicas que podrían llegar a crear los piercings orales y periorales (Tabla 1):

\section{DURANTE EL PROCESO DE PERFORACIÓN}

1. Sangrado incontrolado: La mucosa especializada lingual esta ricamente irrigada principalmente la arteria y la vena lingual, y sus vasos. Normalmente es un sangrado controlado rápidamente, aunque se han descrito casos de hemorragias extremas, descritas por Reichl y Harrison en 1997 y por Hardee et al en 2003, que deberían de recibir una atención inmediata (14).

2. Nervio dañado o parestesias: La lengua esta ampliamente inervada por el trigémino. Tiene dos tipos de inervación, la motora, que procede de los nervios hipogloso mayor y glosofaríngeo, y la sensitiva, que viene de los nervios lingual, glosofaríngeo y neumogástrico. Brennan lo clasificaría como una lesión poco frecuente (5). Es posible atravesar un nervio durante el proceso, es más frecuente cuando se perfora la parte dorso lateral que la dorsoventral, pero también podría ocurrir, si esto ocurriese, podría creo daños sensoriales o motores en función de nervio dañado (3) e incluso llegar a crear una parestesia.

3. Enfermedades de transmisión: Todo el material, equipos y suplementos, debe estar correctamente estéril para evitar transmisión de enfermedades tales como el Sida, hepatitis B y C (las más trasmitidas), cándida albicans, herpes sim-

\section{TABLA 1}

\section{Durante el proceso}

1. Sangrado incontrolado.

2. Nervio dañado o parestesias.

3. Enfermedades de transmisión.

\section{A corto plazo}

1. Inflamación, dolor e infección local de la lengua.

2. Alteraciones radiográficas.

3. Trauma sobre la encía: Eritema y edema.

4. Alergia.

5. Bacteriemia.

6. Angina de Ludwig.

\section{A largo plazo}

1. Acúmulo de placa bacteriana y sarro $\rightarrow$ halitosis.

2. Ingestiones y aspiraciones.

3. Alteración del habla y la masticación.

4. Hiperplasia tisular.

5. Malposición dentaria.

6. Dehiscencia y pérdida ósea.

7. Traumas, fisuras y fracturas.

8. Fibroma traumático, hiperplasia fibrosa inflamatoria, quiste de retención mucosa.

9. Sialorrea.

10. Corrientes galvánicas.

11. Desgarros.

12. Recesión gingival.

13. Endocarditis.

ple, enf. Einster-Barr (mononucleosis), tétanos, sífilis, tuberculosis $(1,3,6)$.

\section{A CORTO PLAZO}

1. Inflamación, dolor e infección local de la lengua: Los tejidos que rodean al piercing tras la perforación, están inflamados y ulcerados creando dolor. La inflamación y el dolor son las complicaciones más frecuentes $(6,8)$. Tras 6-8 horas postprocedimiento comienza un proceso inflamatorio local, alcanzando su auge a los 3-4 días 
posteriores a la intervención. La inflamación puede alargarse varias semanas. Según Berenguer en el 2006 sería común encontrar inflamación severa tras la perforación (7) y Levin calculó que la infección era común en un $9 \%$ de los portadores; y que el paciente presentase inflamación y sangrado después del piercing era casi común en la mitad de los casos (8). Los agentes causales más frecuentes de las infecciones son los estafilococos aureus, los estreptococos del grupo A y las pseudomonas (15). El tiempo necesario para que remitan totalmente los síntomas de dolor tras una perforación lingual se calcula entre 3 y 5 semanas (16). Otro factor que hay que tener en cuenta es la proximidad de las cadenas ganglionares submaxilares y submental a la zona y si se crea una infección se podría diseminar fácilmente, produciendo un deterioro en el habla e incluso obstruyendo la vía aérea.

2. Alteraciones radiográficas: Debe de retirarse previo a una exploración radiográficas, debido a las imágenes radiodensas que puede producir en el frente anterior principalmente, provocando un impedimento a la hora de ver determinadas estructuras. En las radiografías panorámicas debe de retirarse cualquier objeto metálico por encima del cuello. Los piercings de la mejilla o del labio deben ser retirados antes de realizar radiografías periapicales o de aleta de mordida.

3. Trauma sobre la encía: Eritema y edema: El eritema localizado, resultó la afección más encontrada en implantaciones bucales con 23,80\% (2).

4. Alergia: El metal del que esta constituido la joya podría ocasionar una reacción alérgica, angioedema, actuando como alergeno, el cuerpo libera histamina y otras sustancias químicas al torrente sanguíneo como reacción del sistema inmune. Varios autores consideran que la reacción alérgica más común es la dermatitis de contacto. Como ya hemos esquematizado con anterioridad hay elementos como el níquel o el cromo o el níquelcobalto, que son mejor no usarlos como material de elección para un piercing debido al la elevada probabilidad de reacciones alérgicas. Un estudio realizado por Lhotka et al. mostró una hipersensibilidad al níquel en el $18 \%$ de hombres y en el $23 \%$

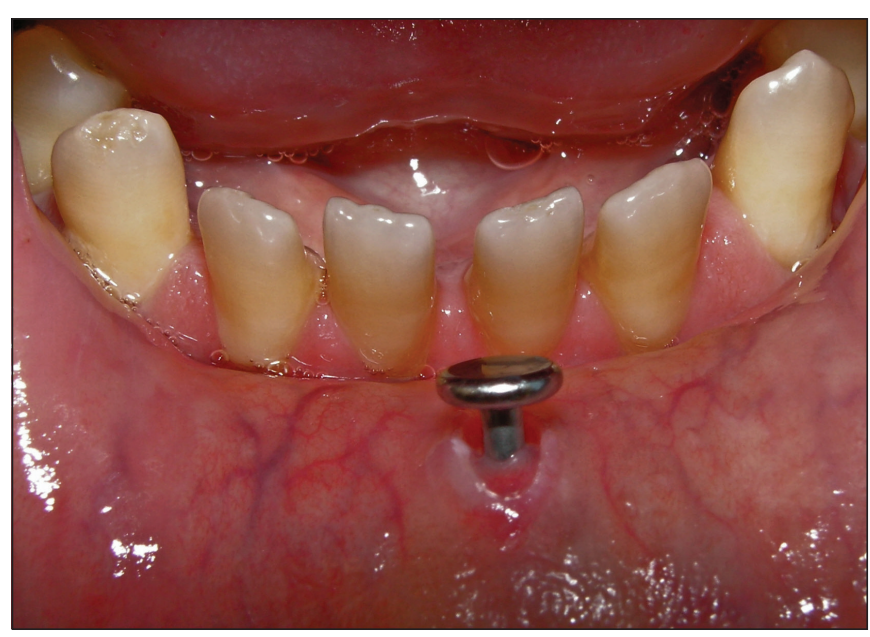

Fig. 10. Trauma sobre la mucosa que cursa con edema y eritema.

de mujeres junto con elevados índices de hipersensibilidades a otras sustancias como el cromo que hasta ese momento formaban parte de la mayoría de los piercing orales y periorales. Según una directiva de la Unión Europea, a mediados de la década de los noventa, se restringió el uso de níquel en todos los productos que estuvieran en contacto directo con los tejidos humanos.

5. Bacteriemia: La bacteriemia, presencia de bacterias en el flujo sanguíneo, es una situación frecuente y normalmente no provoca síntomas; aunque si se presentan síntomas como fiebre, escalofríos, temblores y un enrojecimiento circundante a la perforación. Las bacterias que entran en el flujo sanguíneo, por lo general, son rápidamente eliminadas por los glóbulos blancos. Sin embargo, en ciertos casos, la cantidad de bacterias es demasiado grande como para que puedan ser eliminadas fácilmente y aparece una infección llamada sepsis, que causa síntomas graves. En algunos casos, la sepsis desemboca en una situación que puede ser mortal y que recibe el nombre de shock séptico. Tras una colocación reciente, se deberá solicitar atención sanitaria si aparecen síntomas de bacteriemia como fiebre, escalofríos, temblores y un enrojecimiento circundante a la perforación.

6. Angina de Ludwig: Es un tipo de celulitis aguda que cursa con una inflamación en la región sub- 
maxilar y submental (17) e infección bacteriana aguda, agresiva, de instauración y diseminación rápidas y progresiva. Bilateral. Camener le dio ese nombre en 1837 designando a un caso clínico similar de W. F. von Ludwig 1 año antes. Caracterizada por su topografía y su clínica: induración de tejidos situados debajo de lengua, provocando un desplazamiento de ésta hacia arriba y atrás, sin fluctuación ni dolor inicial. Movilidad mandibular. Presenta dificultad al deglutir y en la fonación. Puede cursar con una grave afectación general, excediendo temperaturas superiores a $40^{\circ} \mathrm{C}$. Posee una fácil comunicación con espacios pterigomandibular y perifaríngeos facilitando de esta forma la propagación de la infección a zonas cervicales vecinas, pudiendo llegar a afectar al mediastino. Casos de angina causada por piercing orales fueron descritos por (18).

\section{A LARGO PLAZO}

1. Acúmulo de placa bacteriana y sarro: El piercing es una zona de retención de restos alimenticios, y de higiene más compleja; por ello es un foco de bacterias que llegan a causar halitosis. El piercing provoca acumulación de placa y cálculo (7). Los restos de comida y cálculo se acumulan en el área del piercing y en la cara de la joya promoviendo la infección (8). La perforación lingual con un barbell puede provocar acúmulos de placa y cálculo supra y subgingival en dientes anteroinferiores debido a que la esfera inferior del piercing contacta continuamente con los dientes (13).

2. Ingestiones y aspiraciones: Provocadas por una mala fijación, mala manipulación durante su colocación o por movimientos con gran presión, pueden ocasionar lesiones respiratorias o digestivas (6). Si se requiere anestesia general para una intervención quirúrgica existe la controversia sobre la necesidad o no de retirar el piercing (sobre todo los linguales); durante la anestesia el piercing podría ser aspirado, traumatizar los tejidos o ser un obstáculo en la intubación. Al retirarlo, un método simple para evitar que la perforación se cierre, es la colocación de un hilo de nylon o un catéter epidural muy fino a modo de anillo (6).

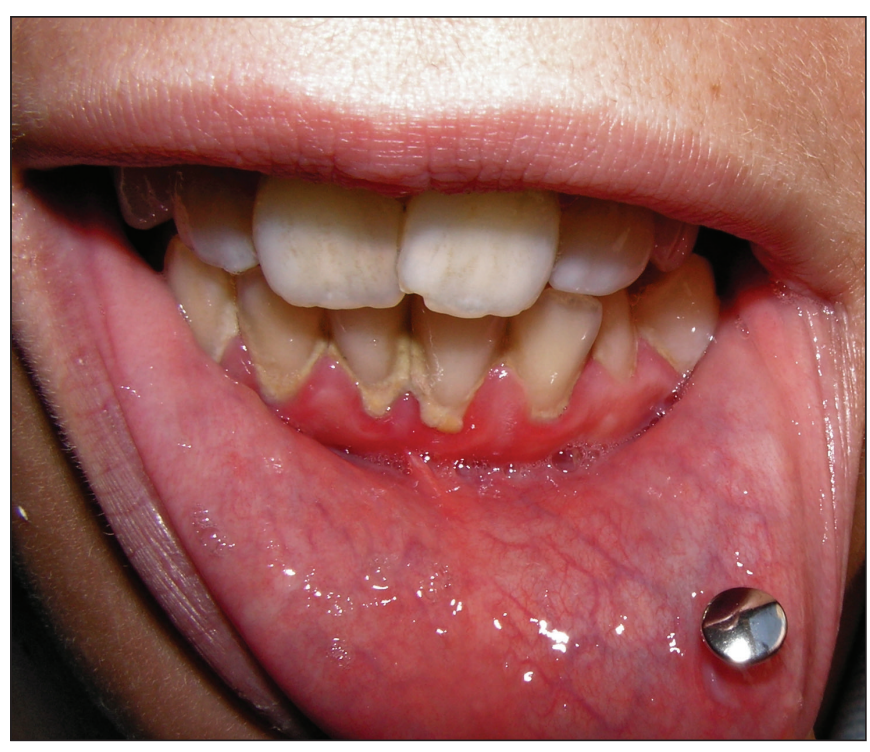

Fig. 11. Placa en la zona anteroinferior donde está situado el piercing.

3. Alteraciones del habla y la masticación: Con los piercings puede ser habitual, en lugares como la lengua, que haya una mayor dificultad al masticar, hablar y pronunciar, sobre todo letras como la $s, s h$, th, ph, $t$ y $v(3,4,6,8,19)$.

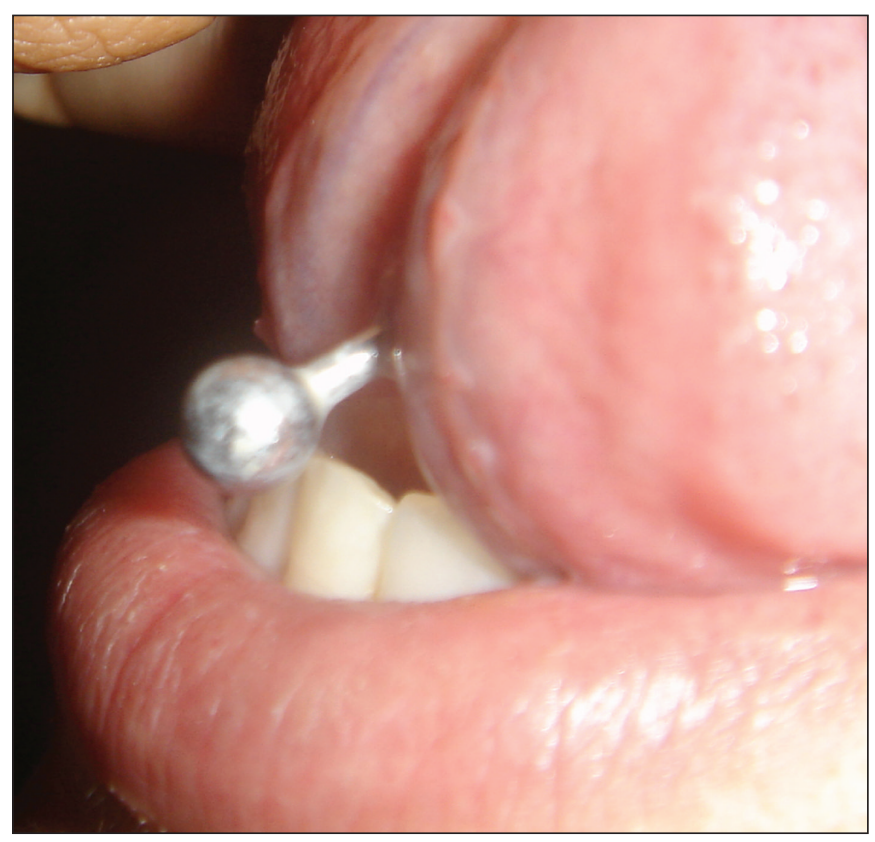

Fig. 12. Barbel en zona lingual con placa. 
4. Hiperplasia tisular y epitelizaciones: Puede ir acompañado de dolor y edema (3). La perforación de los tejidos blandos puede cicatrizar de forma hiperplásica (6). Un factor que puede contribuir a las lesiones hiperplásicas es el movimiento continuado del piercing en el tejido sobre el que se inserta (16). La herida causada por la colocación del piercing puede evolucionar, tras varios meses, con el recubrimiento epitelial del mismo, complicando el momento de su retirada (6).

5. Malposición dentaria: Sólo una revisión de la literatura consultada, de Urbiola et al ha relacionado el piercing oral, lambret, con una linguoversión de incisivos inferiores debido a un desequilibrio de fuerzas musculares (6).

6. Dehiscencia y Pérdida ósea: Un piercing puede llegar a provocar una pérdida ósea horizontal localizada por el trauma constante que hace la joya (8). La bola del lambret o del barbell puede estar en continuo roce contra la encía mandibular provocando una dehiscencia ósea (3).

7. Traumas, fisuras y fracturas: Son las lesiones más frecuentes descritas por el uso de los piercings intraorales (14). El hábito de empujar y jugar con el pendiente contra los dientes o, simplemente, el hecho de tener un objeto extraño en la boca puede ocasionar fracturas, fisuras, abrasiones o desprendimientos de espículas de esmalte provocando, sobre todo si existe implicación pulpar, sensibilidades a substancias frías o dulces o al respirar (5) y la aparición de dolor al ejercer una presión en el diente afectado. De Moore et al. registraron en un $80 \%$ de pacientes con un piercing lingual alguna pérdida en su estructura dentaria (14). Podíamos clasificarlo también en complicaciones durante el tratamiento, ya que durante la anestesia para la colocación del piercing en lengua, se provoca un bloqueo nervioso y ésta pierde sensibilidad y podía provocar una fractura de los dientes (5). Estas complicaciones dentarias son más frecuentes en los portadores de barbells linguales, sobre todo en la zona de molares e incisivos inferiores; que en los piercings labiales (6). En los portadores de coronas de porcelana o con hábitos parafuncionales como

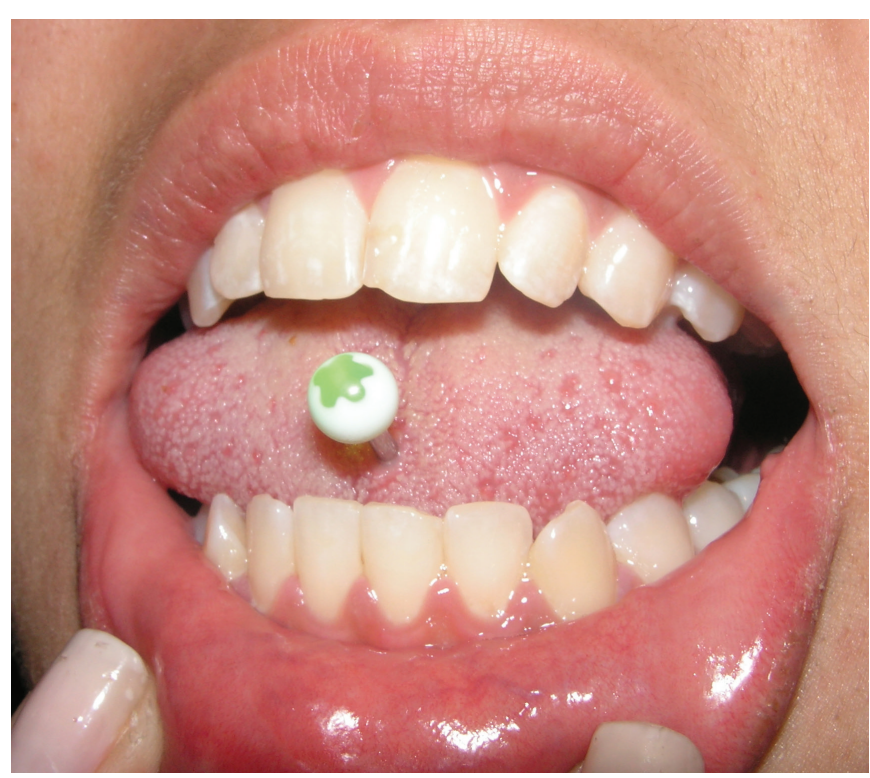

Fig. 13. Fractura del ángulo mesiovestibular del 21 y distovestibular de 31 causado por traumatismo del piercing.

el bruxismo, aumenta mucho el riesgo de fracturas o desgastes $(20,14)$. Levin et all en el año 2005 publicó que una de las complicaciones que podía ocasionar el piercing oral era las fracturas del diente y las abrasiones (8). El retirar o no el piercing ante una anestesia local dependerá del criterio de cada profesional. En las anestesia tronculares que llegan a afectar hasta a la lengua, ésta podría llegar a producir una fractura o trauma. También la joya puede provocar daño a las restauraciones de piezas dentales (4).

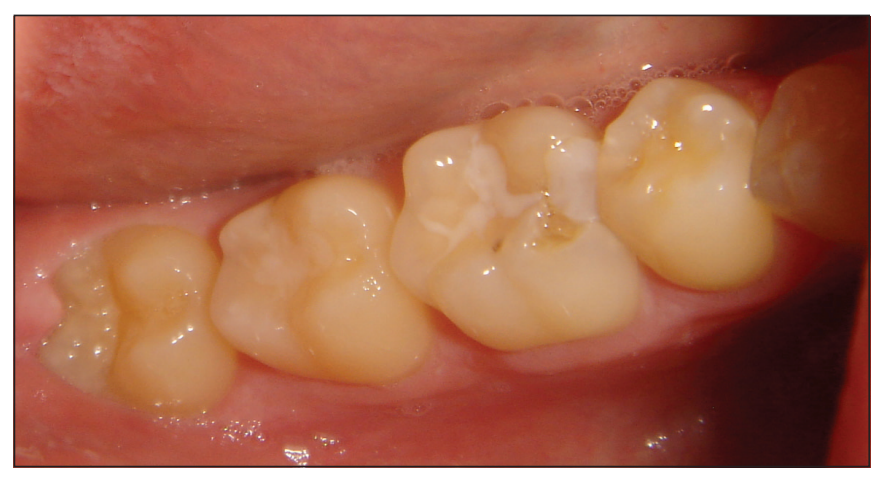

Fig. 14. Fractura de la cúspide mesiovestibular del primer molar inferior al morder el piercing con ella. 


\section{Fibroma traumático, hiperplasia fibrosa infla-} matoria, quiste de retención mucosa: Jiménez et al describe un caso de fibroma traumático causado por piercing lingual diagnosticado tras una biopsia excisional (4). La persistencia de estos aditamentos en boca da origen a lesiones que van desde un edema, hasta lesiones reactivas tipo Fibromas, mucoceles o hiperplasias fibrosas inflamatorias (4).

9. Sialorrea: El piercing oral provoca hipersalivación según autores, tales como Venta I et al. (10), que comprobó con un estudio de 234 alumnos del primer año de universidad de Helsinki, que el $63 \%$ de estos tenían piercing oral tenían un incremento en el índice de saliva. Otros estudios también incluyen al aumento de flujo salivar como una de las posibles complicaciones causadas por éstos $(1,4,6,8)$.

10. Corrientes galvánicas: En el artículo de Levin et al comentan un caso de galvanismo provocado por el contacto de una amalgama de plata y piercing de acero inoxidable (8). La corriente galvánica del piercing metálico en contacto con restauraciones metálicas podría producir sensibilidad pulpar (19).

11. Desgarros: Los desgarros fueron las complicaciones peribucales más frecuentes $(31,2 \%)$, en su estudio de 425 estudiantes de educación secundaria y preuniversitaria El Universo estuvo constituido por 425 estudiantes de Educación Secundaria y Preuniversitaria con edades entre 11 y 17 años (2).

12. Recesión gingival: Leichter indica que hay más recesión en una persona con piercing que sin él y que los casos que se presentan son de personas con clases II y III de Miller (11). En el estudio de Brooks et al. (6) se describen una serie de casos de recesión gingival por piercings; los colocados en la lengua provocaban la recesión en la cara lingual de los incisivos anteroinferiores junto con un aumento en la profundidad de las bolsas periodontales; los piercings colocados en el labio inferior provocaron recesiones en la cara vestibular de los incisivos inferiores sin aumentar la profundidad de las bolsas periodontales. El desarro-

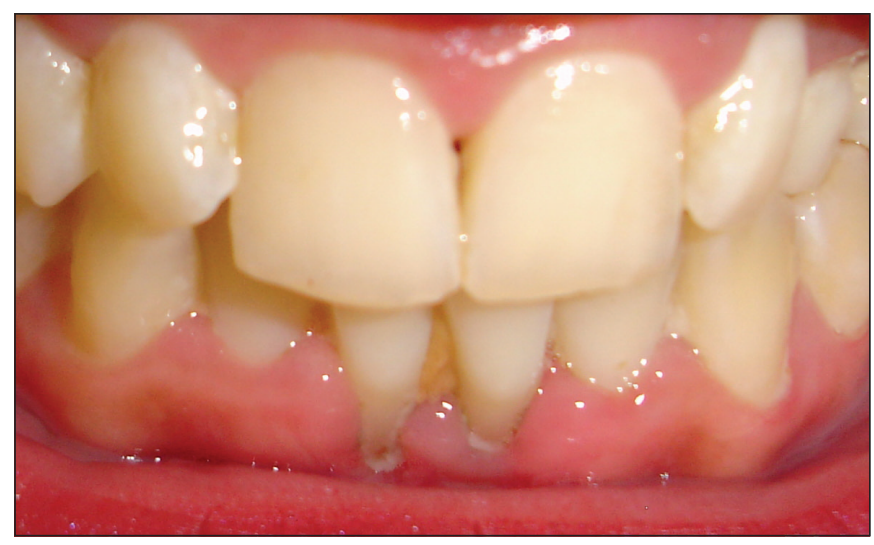

Fig. 15. Paciente con recesión gingival en los incisivos inferiores causada por un labret, al aparecer una gran recesión, pérdida ósea y movimiento de las piezas, se tuvo que optar por la retirada de éste.

llo de las recesiones en la cara vestibular de los incisivos inferiores puede desarrollarse entre los 6 meses y los dos años tras la colocación del piercing. Según Agel et al, en un estudio de 52 adultos jóvenes se encontró recesión gingival en el $35 \%$ de los sujetos que tenían piercing en la lengua durante 4 años o más y $50 \%$ que usaban piercing de barra larga $(2,2 \mathrm{~cm})$ durante 2 o más años (19). Ventä et al comprobaron en su estudio que la recesión gingival se producía con mayor incidencia a partir de los dos años, sobre todo si el barbell era largo (10).

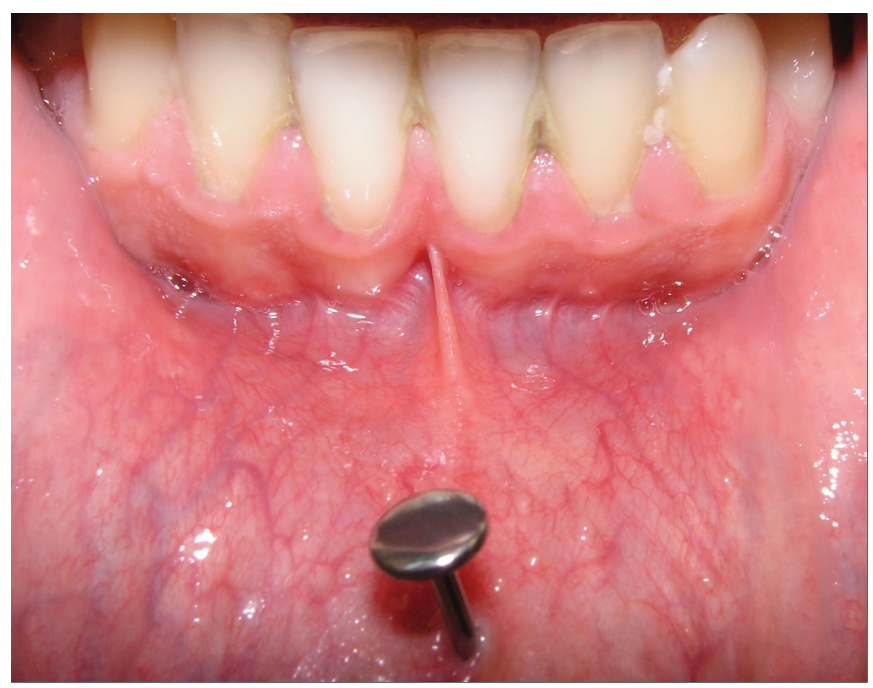

Fig. 16. Recesión gingival de los incisivos centrales inferiores. 
13. Endocarditis: Como ya hemos marcado con anterioridad en el apartado de contraindicaciones, se han visto casos de endocarditis valvulares en pacientes que han sufrido una alteración cardíaca con anterioridad y no estaban medicados (13).

\section{TRATAMIENTO}

Ante la presencia de sangrado incontrolado, el tratamiento correcto sería recibir una atención inmediata.

Si se transmiten enfermedades a través de la colocación del piercing el tratamiento irá en función de esa patología.

Si existiese el paciente presenta una inflamación y dolor fuertes de la lengua causada por el piercing prolongadamente habría que quitar la joya, prescribir enjuagues como la clorhexidina, antiinflamatorios sistémicos, en algunos casos, desbridamiento profiláctico de los espacios afectados y recetar antibióticos; todo ello unido a un posterior seguimiento del paciente $(8,6)$. Cuando la inflamación de la lengua se presenta de forma generalizada, afectando a la faringe u órganos contiguos o comprometa a la deglución o respiración, el tratamiento será urgente con la administración de antibióticos y corticoides sistémicos (6).

Para que no hubiese ningún tipo de alteraciones radiográficas sería recomendable que el paciente retire el piercing, avisándole previamente del riesgo de cierre de la perforación, o colocándole hilo de nylon o un catéter epidural para evitarlo; ya que, como hemos citado anteriormente, no nos dejaría ver determinadas estructuras, y si vamos a realizar una panorámica, todo objeto metálico por encima del cuello debe ser retirado.

Ante cualquier signo o síntoma de alergia, el piercing oral o perioral debe ser retirado.

Si el piercing provoca al paciente una angina de Ludwig, el tratamiento debe ser hospitalario, enérgico y multidisciplinario, con antibiótico terapia intensa acompañada de ciertas medidas, dependiendo de su gravedad, como es el desbridamiento profilác- tico de todos los espacios afectados y el control del grado de dificultad respiratoria.

Ante la presencia de un acúmulo de placa bacteriana, cálculo supra o subgingival, recesiones gingivales y movilidad dentaria, deberemos aconsejar también la retirada del piercing; además daremos instrucciones de higiene oral, realizaremos una profilaxis y un raspaje y alisado radicular en la región afectada con el fin de reducir la inflamación, el sangrado gingival y la posible pérdida de soporte óseo (6).

Si se requiere anestesia general existe el dilema sobre la necesidad o no de retirar el piercing, sobre todo en caso de tener piercing linguales ya que podrían ser aspirados, traumatizar los tejidos o ser un obstáculo en la intubación.

Si la alteración del habla, fonación y la masticación son muy exageradas, habría que retirar el piercing para solucionar este problema.

En el caso de provocar una dehiscencia o pérdida ósea habría que quitar el piercing de inmediato para evitar la inestabilidad del diente.

El quitar o no el piercing para una anestesia troncular dependerá, como ya hemos mencionado anteriormente, del criterio del profesional, ya que la probabilidad de una fractura dentaria, por pérdida de sensibilidad de la lengua, se incrementa. Para evitar fracturas y desgastes dentarios diarios lo ideal sería recomendar al paciente la retirada del piercing o como alternativa el uso de barbells linguales de tallo más corto, ya que como hemos dicho con anterioridad hay menor incidencia de traumatismos que con los de tallo largo (6) o piercing de plástico antes que metálicos. El tratamiento conservador deberá restaurar la superficie afectada y realizar una endodoncia si hay afectación pulpar; tras la restauración dentaria, la fractura puede recidivar, por fractura de la restauración, o incrementarse en poco tiempo si no se retira el piercing, pudiendo llegar a provocar pérdidas de cúspides o fracturas verticales de la pieza dental. El paciente puede tener un hábito jugando con el piercing y provocando un trauma continuo, si es así, se podría ofrecer al paciente la posibilidad de un protector dental $(3,6)$. 


\begin{tabular}{|c|c|c|c|}
\hline Pauta estándar: & Amoxicilina $2 \mathrm{gr}$ & vía oral & $\rightarrow 1 \mathrm{~h}$ antes \\
\hline Alérgicos a penicilina: & $\begin{array}{l}\text { Clindamicina } 600 \mathrm{mg} \\
\text { Cefalexina/Cefadroxilo } 2 \mathrm{gr} \\
\text { Aritromicina/Claritromicina } 500 \mathrm{mg}\end{array}$ & $\begin{array}{l}\text { v.o } \\
\text { v.o } \\
\text { v.o }\end{array}$ & $\begin{array}{l}\rightarrow 1 \mathrm{~h} \text { antes } \\
\rightarrow \quad 1 \mathrm{~h} \text { antes } \\
\rightarrow \quad 1 \mathrm{~h} \text { antes }\end{array}$ \\
\hline Intolerancia a vía oral: & Ampicilina $2 \mathrm{gr}$ & $\begin{array}{l}\text { v. intramuscular } \\
\text { v. intravenosa }\end{array}$ & $\begin{array}{l}\rightarrow 30 \text { min antes } \\
\rightarrow 30 \text { min antes }\end{array}$ \\
\hline $\begin{array}{l}\text { Alérgicos a penicilina con } \\
\text { intolerancia a vía oral: }\end{array}$ & $\begin{array}{l}\text { Clindamicina } 600 \text { mg } \\
\text { Cefazolina } 1 \mathrm{gr}\end{array}$ & $\begin{array}{l}\text { vía e.v } \\
\text { vías e.v o im }\end{array}$ & $\begin{array}{l}\rightarrow 30 \text { min antes } \\
\rightarrow 30 \text { min antes }\end{array}$ \\
\hline
\end{tabular}

Si se producen corrientes galvánicas las soluciones que tendría el paciente sería cambiar el material del empaste de amalgama de plata a composite, o bien cambiar el material del piercing por otro diferente al metal.

Si se produce un desgarro habrá que proceder a la retirada del piercing y a la cura de la herida provocada por este, con enjuagues para acelerar la cicatrización y evitar la infección de la zona.

La progresión de la recesión gingival se detiene con la retirada del piercing, aunque el tratamiento definitivo implicaría cirugía mucogingival en los casos en los que necesitásemos un control de la inflamación gingival, debida al microtraumatismo de repetición causado por el piercing; para evitar el avance de una recesión; si hubiese localizaciones con sensibilidad de tejidos blandos al cepillarse o a la masticación (21), requerimientos estéticos del paciente o hipersensibilidad radicular (22). Las técnicas quirúrgicas que podríamos emplear para la cirugía mucogingival serían las siguientes (22):

— Injertos libres (autógenos): I. L. de encía y de tejido conectivo.

- Injertos pediculados: Colgajo de reposición lateral, oblicuo-rotado, de doble papila.

Para cualquier persona susceptible de endocarditis con alguna patología cardíaca anterior, deberán de seguirse algunas medidas profilácticas previas a la colocación del piercing para adultos según American Heart Association (1997) (Tabla 2).

\section{CONCLUSIONES}

Ha habido un aumento de pacientes en clínicas odontológicas con piercing orales y periorales en estos últimos años y estos deberían de tener un seguimiento más exhaustivo debido a las posibles complicaciones que acarrean los piercing orales y periorales, ya que estos pueden dar patologías muy variadas desde una leve inflamación local hasta grandes infecciones diseminadas, enfermedades de transmisión, etc.

Antes de ponerse un piercing el odontólogo debe informar sobre las posibles patologías y sobre todas las medidas preventivas para evitar las posibles complicaciones que implican los piercings orales y periorales, las localizaciones donde hay mayor incidencia de complicaciones, los cuidados que hay que llevar a cabo, las condiciones de asepsia e instrumental estéril del lugar en el que se vaya a hacer.

\section{BIBLIOGRAFIA}

1. Huber MA, Terezhalmy GT, Moore WS. Oral/perioral piercing. Quintessence Int. 2003; 34(9): 722-3.

2. Maresma Frómeta R, Rodríguez D, Mainegra R, Navarrete H. Hallazgos clínicos asociados al piercing bucal y peribucal. Progaleno.

3. Troye Peticolas, RDH, BS; Terri SI, RDH, MS, MA; Gail N. Cross-Poline, RDH, MS, MA. Oral and Pe- 
rioral Piercing: A unique form of self-expression. The journal of temporary dental practice. Summer Issue 2000 (1): 3.

4. Jiménez C, Perez C, Kilikan R, Avilés D, Pérez L. Piercings: Manifestaciones bucales. Revista latinoamericana de ortodoncia y odontopediatría.

5. Brennan M, O'Connell B, O'Sullivan M.Multiple dental fractures following tongue barbell placement: a case report. Dent Traumatol. 2006; 22(1):41-3.

6. Urbiola Alís I, Viñals Iglesias H. Algunas consideraciones acerca de los piercings orales. Av Odontoestomatol v. 21 n.5 Madrid. 2005.

7. Berenguer G, Forrest A, Horning GM, Towle HJ, Karpinia K.Localized periodontitis as a long-term effect of oral piercing: a case report.Compend Contin Educ Dent. 2006;27(1):24-7.

8. Levin L, Zadik Y, Becker T. Oral and dental complications of intraoral piercing. Dental Traumatology 2005;21:341-3.

9. Sean T, Carroll MD, Riffenburgh RH, Roberts TA, Myhre EB. Tattoos and body piercings as a indicators of adolescent risk-taking behaviours. Pediatrics, 2002; 109 (6): 1021-7.

10. Vent I, Lakoma A, Haahtela S, Peltola J, Ylipaavalniemi P, Turtola L.Oral piercings among first-year university students. Oral Surg Oral Med Oral Pathol Oral Radiol Endod. 2005;99(5): 546-9.

11. Leichter JW, Monteith BD.Prevalence and risk of traumatic gingival recession following elective lip piercing. Dent Traumatol. 2006;22(1):7-13.

12. http://w3.cnice.mec.es/recursos2/estudiantes/jovenes/op_38.htm
13. Dubose J, Pratt JW. Victim of fashion: Endocarditis after oral piercing. Current Surgery. 2004; 61(5):474-7.

14. De Moore RJG, De Witte AMJC, De Bruyne MAA. Tongue piercing and associated oral and dental complications. Endod Dent Traumatol 2000; 16:232-7.

15. Guiard-Schmid JB, Picard H, Slama L, Maslo C, Amiel C, Pialoux G, Lebrette MG, Rozembaum W. Piercing and its infectious complications. A public health issue in France. Press Med 2000 18;29(35):1948-56.

16. Boardman R, Smith RA. Dental implications of oral piercing. Ca Dent Ass J, 1997;25(3):203-7.

17. Bascones Martínez A. Medicina bucal. Barcelona: Ariel. 2004:582.

18. Peticolas T, Tilliss TSI, Cross-Poline GN. Oral and perioral piercing: A unique form of self expression. J Contemp Dent Pract, 2000;1(3):1-10.

19. Agel A, Acosta J, Longobardi P, Sorbe R. Piercing labial: Factor etiológico de recesión gingival. Revista latinoamericana de ortodoncia y odontopediatría. 2001.

20. Botchway C, Kuc L. Tongue piercing and associated tooth fracture. J Can Dent Assoc, 1998;64:803-5.

21. Lindhe. Periodoncia clínica e implantología odontológia. Madrid. Panamericana 2005:613.

22. Bascones Martínez.A. Periodoncia clínica e implantología oral. Madrid. Avances. 2001:537-8.

23. Lhotka CG,Szekeres T, Fritzer-Szekeres M, Schwraz G, Steffan I, Maschke M, et al. Are Allergic Reactions to Skin Clips associated with delayed Wond Healing? Am J Surg, 1998; 176 (4):320-3. 